\title{
Comparison of Antioxidant Status and Vitamin D Levels between Multiple Sclerosis Patients and Healthy Matched Subjects
}

\author{
Ehsan Hejazi, ${ }^{1}$ Reza Amani, ${ }^{2}$ Naser SharafodinZadeh, ${ }^{3}$ and Bahman Cheraghian ${ }^{4}$ \\ ${ }^{1}$ Department of Clinical Nutrition and Dietetics, Faculty of Nutrition Sciences and Food Technology, \\ National Nutrition and Food Technology Research Institute, Tehran, Iran \\ ${ }^{2}$ Department of Nutrition, School of Para Medicine, Diabetes Research Center, Jundishapur University of Medical Sciences, \\ Ahvaz 61357-15794, Iran \\ ${ }^{3}$ Department of Neurology, Golestan Hospital, Jundishapur University of Medical Sciences, Ahvaz, Iran \\ ${ }^{4}$ Department of Epidemiology, School of Public Health, Jundishapur University of Medical Sciences, Ahvaz, Iran \\ Correspondence should be addressed to Reza Amani; rezaamani@hotmail.com
}

Received 16 January 2014; Revised 25 February 2014; Accepted 24 March 2014; Published 14 April 2014

Academic Editor: Wolfgang Bruck

Copyright @ 2014 Ehsan Hejazi et al. This is an open access article distributed under the Creative Commons Attribution License, which permits unrestricted use, distribution, and reproduction in any medium, provided the original work is properly cited.

Objective. The aim of the present study was to compare the serum levels of total antioxidant status (TAS) and 25(OH) D3 and dietary intake of multiple sclerosis (MS) patients with those of normal subjects. Method. Thirty-seven MS patients (31 women) and the same number of healthy matched controls were compared for their serum levels and dietary intake of $25(\mathrm{OH}) \mathrm{D} 3$ and TAS. Sun exposure and the intake of antioxidants and vitamin D rich foods were estimated through face-to-face interview and food frequency questionnaire. Results. Dietary intake of antioxidants and vitamin D rich foods, vitamin C, vitamin A, and folate was not significantly different between the two groups. There were also no significant differences in the mean levels of 25(OH) D3 and TAS between the study groups. Both groups had low serum levels of $25(\mathrm{OH}) \mathrm{D} 3$ and total antioxidants. Conclusion. No significant differences were detected in serum levels and dietary intake of vitamin $\mathrm{D}$ and antioxidants between MS patients and healthy controls. All subjects had low antioxidant status and vitamin D levels.

\section{Introduction}

Multiple sclerosis (MS) is an autoimmune, inflammatory, and demyelinating disease which can cause significant disability among young adults $[1,2]$. The etiology of MS has not been fully understood yet; however, it is believed that immunological mechanisms are the most important factors in initiation and progression of the disease [3]. It is generally accepted that vitamin D status is related to both innate and adaptive immune system [4]. There is considerable body of evidence, including prospective cohort studies, that shows that increased levels of sun exposure [5], greater dietary vitamin D intake [6], or higher levels of serum 25(OH) D3 are correlated with a lower risk of MS onset. Several studies have demonstrated the preventive effect of vitamin $\mathrm{D}$ on the onset or development of animal model of MS, experimental autoimmune encephalomyelitis (EAE) $[7,8]$. It has been also proven that oxidative stress has an essential role in the inflammatory processes and in the pathogenesis of MS [9]. Oxidative and nitrosative stress may cause selective oligodendrocyte death, and thereby demyelination. The reactive species may also damage the myelin sheath, promoting its attack by macrophages [8]. It has been also reported that free radicals are necessary to phagocytize myelin by macrophage as well [10]. Furthermore, because of the vulnerability of the Central Nervous System (CNS) to the reactive oxygen species (ROS), decreased cellular antioxidant defense in CNS can increase the injury observed in MS [11]. Measurement of serum concentrations of different oxidant species can be time consuming and expensive; hence, total antioxidant status (TAS) is an effective estimate of the activity of blood antioxidants [12]. Studies on patients with MS with 
respect to serum $25(\mathrm{OH}) \mathrm{D} 3$ and 1, 25-(OH)2 D3 and TAS concentrations are rare. Therefore, in this case control study, we have evaluated blood concentrations of hydroxyl vitamin $\mathrm{D}$ and TAS and also dietary intakes of the main antioxidants and vitamin D sources in MS patients and age- and sexmatched healthy controls.

\section{Materials and Method}

Thirty-seven patients with relapsing-remitting multiple sclerosis (RRMS), who were referred to the Clinic of Neurology in Golestan Medical Center, Ahvaz Jondishapur University, by a Neurologist (NSZ), were enrolled in the present casecontrol study. Diagnosis was confirmed on the basis of MRI and clinical or laboratory-supported diagnosis of definite RRMS MS [13]. All patients were in remitting phase and their Expanded Disability Status Scale (EDSS) was low (EDSS < 4.5).

Thirty-seven sex- and age-matched controls were recruited from healthy blood donors in the same urban catchment area. All participants in this study were living for a long time in the city of Ahvaz.

Exclusion criteria for both groups were having hepatic or renal diseases, type 1 diabetes, heart disease, hypercortisolism, and pregnancy, and also intake of multivitamin supplements, alcohol consumption, and Smoking. Five patients were excluded from the study because of the difficulty in measurement of their vitamin D and TAS levels. After an overnight fasting, whole blood samples of patients were drawn. The serum samples were then stored at $-20^{\circ} \mathrm{C}$ and protected from direct exposure to sunlight until further analysis. Serum 25 hydroxy vitamin D concentrations were measured using RIA method (Biosource Europe) [12, 14]. Vitamin D levels equal to or below $12.5 \mathrm{nmol} / \mathrm{L}$ were considered as severe deficiency. Concentrations between $12.5 \mathrm{nmol} / \mathrm{L}$ and $25 \mathrm{nmol} / \mathrm{L}$ were considered as moderate deficiency and levels between $25 \mathrm{nmol} / \mathrm{L}$ and $35 \mathrm{nmol} / \mathrm{L}$ were regarded as mild deficiency [14]. Plasma TAS was measured by Hitachi Analyzer with a Randox reagent set (England). The radical cation obtained has a relatively stable bluegreen color, which is measured at $600 \mathrm{~nm}$. Antioxidants contained in the serum sample suppress the formation of this color [15]. The subjects were asked to complete a sun light exposure questionnaire which its validity and reliability were confirmed [16]. The questionnaire was containing details about duration of exposure to sun light in the previous month (less than 30, between 30 to 60 , between 60 to 120 , and more than 120 minutes/day), sunscreen cream usage and clothing (exposure of hand and face or more areas). Information about dietary intake of vitamin $\mathrm{D}$ sources and dietary antioxidants was obtained using a semiquantitative food frequency questionnaire [9]. Daily intake of vitamin C, vitamin $\mathrm{E}$, vitamin $\mathrm{A}$, and folate was recorded from a 24-hour dietary recall questionnaire for 3 days ( 2 consecutive and one weekend days). Dietary data were analyzed using Nutritrack software (2004 version). Subjects' weights and heights were measured using a platform digital scale (Seca, Germany) and nonstretchable wall stadiometer, respectively. BMI was
TABLE 1: Basic characteristics, 25(OH) D3 and TAS1 serum levels of study groups*.

\begin{tabular}{lccc}
\hline Variables & Patients $(n=37)$ & Controls $(n=37)$ & $P$ \\
\hline Age $(\mathrm{yr})$ & $32 \pm 0.8$ & $32.2 \pm 7.4$ & 0.9 \\
Sex $(\% \mathrm{~F})$ & 84 & 84 & 1 \\
Height $(\mathrm{cm})$ & $160.8 \pm 8$ & $163.1 \pm 10.3$ & 0.3 \\
Weight $(\mathrm{Kg})$ & $64.2 \pm 10.6$ & $66.5 \pm 3.1$ & 0.4 \\
BMI $\left(\mathrm{Kg} / \mathrm{m}^{2}\right)$ & $24.9 \pm 3.9$ & $24.9 \pm 4.1$ & 1 \\
$25(\mathrm{OH}) \mathrm{D} 3(\mathrm{nmol} / \mathrm{L})$ & $20.67 \pm 16.3$ & $15.8 \pm 8.7$ & 0.1 \\
TAS $(\mu \mathrm{mol} / \mathrm{L})$ & $1 \pm 0.1$ & $1.03 \pm 0.1$ & 0.2 \\
\hline
\end{tabular}

${ }^{*}$ Values are mean \pm SD; TAS: total antioxidant status.

defined as weight divided by squared height $\left(\mathrm{kg} / \mathrm{m}^{2}\right)$. SPSS version 13 was used for statistical analysis and a $P$ value $<0.05$ was considered as statistically significant.

\section{Result}

Thirty-seven patients were recruited in each group. The age ranges of participants were between 18 to 52 years. Eightyfour percent of them were female. All of the participants have completed the requested questionnaires.

Patient demographic characteristics and mean levels of 25(OH) D3 and plasma TAS are presented in Table 1. There were no significant differences in basic variables such as age, sex, BMI, mean levels of $25(\mathrm{OH}) \mathrm{D} 3$, and TAS between the study groups. According to Table 2, there is no relationship between levels of 25(OH) D3 and sun exposure in MS patients. However, in healthy subjects, more sun exposure was related to higher levels of $25(\mathrm{OH}) \mathrm{D} 3(P<0.05)$. Table 3 shows that there is no significant association between fish and egg consumption and serum levels of $25(\mathrm{OH})$ D3. However, in healthy subjects with egg consumption more than 3 times per week, it means that serum vitamin $\mathrm{D}$ concentration was higher compared with those who consumed 1-2 eggs per week. Table 4 shows that daily intake of vitamin C, vitamin E, vitamin $\mathrm{A}$, and folate was not significantly different between the study groups. The intake of all antioxidant vitamins in both groups was well below the dietary reference intake (DRI). However, daily intake of vitamin C in control group was near to RDA.

\section{Discussion}

The aim of the present study was to compare the serum levels of $25(\mathrm{OH}) \mathrm{D} 3$ and TAS, dietary intake of the main antioxidants, and vitamin D sources in MS patients with those of healthy subjects. In the present study, we could not find any significant association between the duration of sunshine exposure and serum levels of $25(\mathrm{OH})$ D3 in the patients. There are only few studies which have compared serum levels of 25(OH) D3 between MS patients and healthy controls [17-20]. Some of them have reported that the serum levels of $25(\mathrm{OH}) \mathrm{D} 3$ in MS patients are lower in comparison with healthy controls [18], whereas in a study by SoiluHänninen et al., no significant differences were observed 
TABLE 2: Comparison of serum vitamin D concentrations based on different sun exposure levels.

\begin{tabular}{lccc}
\hline Sun exposure (minutes/day) & $\begin{array}{c}\text { MS patients } \\
\text { 25(OH) D serum concentrations (nmol/L) }\end{array}$ & $\begin{array}{c}\text { Controls } \\
\text { Number }\end{array}$ & $\begin{array}{c}\text { 25 }(\mathrm{OH}) \text { D serum concentrations (nmol/L) } \\
\text { Number }\end{array}$ \\
\hline Less than 30 & $18.4 \pm 16$ & 20 & $\mathbf{1 2 . 6} \pm \mathbf{5 . 9}$ \\
Between 30 and 60 & $24.2 \pm 29.2$ & 5 & $\mathbf{2 1} \pm \mathbf{7 . 7 ^ { \mathrm { a } }}$ \\
Between 60 and 120 & $26.6 \pm 13.2$ & 10 & $\mathbf{1 0}$ \\
More than 120 & $23.1 \pm 7.2$ & 2 & $\mathbf{4 3 . 6} \pm \mathbf{1 4 . 1}^{\mathrm{a}, \mathrm{b}}$ \\
\hline
\end{tabular}

${ }^{\text {a }}$ Significant differences between those of $<30$ minutes/day of sun exposure (ANOVA, $P<0.05$ ).

${ }^{\mathrm{b}}$ Significant differences between those between 30 and 60 minutes/day of sun exposure (ANOVA, $P<0.05$ ).

TABLE 3: Comparison of serum vitamin D levels based on frequency of dietary vitamin D intakes.

\begin{tabular}{|c|c|c|c|c|c|}
\hline \multirow{2}{*}{ Foods } & \multirow{2}{*}{ Frequency of intake (Per week) } & \multicolumn{2}{|l|}{ MS patients } & \multicolumn{2}{|l|}{ Controls } \\
\hline & & $\begin{array}{c}25(\mathrm{OH}) \mathrm{D} \text { serum } \\
\text { concentrations }(\mathrm{nmol} / \mathrm{L})\end{array}$ & Number & $\begin{array}{c}25(\mathrm{OH}) \mathrm{D} \text { serum } \\
\text { concentrations }(\mathrm{nmol} / \mathrm{L})\end{array}$ & Number \\
\hline \multirow{3}{*}{ Fish } & $\geq 3$ & $23.46 \pm 26.65$ & 6 & 19.5 & 1 \\
\hline & $1-2$ & $19.80 \pm 12.44$ & 20 & $16.92 \pm 9.28$ & 25 \\
\hline & rarely & $22.32 \pm 17.46$ & 11 & $12.34 \pm 7.34$ & 11 \\
\hline \multirow{3}{*}{ Eggs } & $\geq 3$ & $18.89 \pm 14.87$ & 11 & $19.2 \pm 10.99^{*}$ & 14 \\
\hline & $1-2$ & $20.11 \pm 14.97$ & 16 & $12.7 \pm 5.51$ & 18 \\
\hline & rarely & $23.65 \pm 20.59$ & 10 & $16.1 \pm 9.2$ & 5 \\
\hline
\end{tabular}

*Significant differences between those with 1-2 per week intake (ANOVA, $P<0.05$ ).

TABle 4: Daily intake of antioxidant vitamins in study groups obtained from $24 \mathrm{~h}$ recall questionnaire*

\begin{tabular}{lccc}
\hline Variables & Patients $(n=37)$ & Controls $(n=37)$ & $P$ \\
\hline Vitamin A $(\mu \mathrm{g} / \mathrm{d})$ & $429.4 \pm 192$ & $439.7 \pm 181$ & 0.9 \\
Vitamin E $(\mathrm{mg} / \mathrm{d})$ & $6.9 \pm 1$ & $5.57 \pm 1.7$ & 0.3 \\
Vitamin C $(\mathrm{mg} / \mathrm{d})$ & $53.7 \pm 31.9$ & $70.8 \pm 27.4$ & 0.1 \\
Folate $(\mu \mathrm{g} / \mathrm{d})$ & $287.7 \pm 91.8$ & $265.5 \pm 76.1$ & 0.8 \\
\hline
\end{tabular}

${ }^{*}$ Values are mean \pm SD

Note: intake of all antioxidant vitamins was below the DRI recommendations (less than 66\% DRI).

between serum levels of $25(\mathrm{OH}) \mathrm{D} 3$ in MS patients and healthy controls in winter [20]. Our findings are in line with Soilu-Hänninen et al., probably because of the similarity in the time of data gathering and sex of the subjects. In a case control study in Australia [21], it was reported that the patients with higher disability (EDSS* $>6$ ) were more likely to have vitamin $\mathrm{D}$ insufficiency compared with controls $(\mathrm{OR}=3.07(1.37,6.90))$; however, there were no differences between the serum levels of $25(\mathrm{OH}) \mathrm{D} 3$ of patients with lower disability (EDSS > 3) and controls. Since the majority of patients (65\%) in the present study had low disability (EDSS $<3$ ), lack of the significant differences between the 2 groups is in agreement with the latter study. In a case control study by Shaygannejad, lower levels of serum $25(\mathrm{OH}) \mathrm{D} 3$ in MS patients compared with healthy controls were reported [17]; however, the severity of the disease was not considered in this study.

In the present study, severe vitamin D deficiency $(25(\mathrm{OH})$ D3 $<12.5 \mathrm{nmol} / \mathrm{L}$ ) was observed in about one-third of the participants (33\% of patients versus $37 \%$ of controls), and most of the subjects ( $66 \%$ versus $73 \%$ of patients and controls, resp.) had moderate vitamin $\mathrm{D}$ deficiency. Several studies have reported high prevalence of vitamin D deficiency in MS patients $[17,18,20,22]$. High prevalence of vitamin D deficiency in Iran and other countries in the Middle East was reported in several previous studies [16]. Hashemipour et al. have shown vitamin D deficiency in $81 \%$ of Tehranian healthy donors [16]. In Saudi Arabia and Lebanon, despite abundant sun exposure, high prevalence of vitamin D deficiency has been also reported [23]. Possible justifications for this finding could be pollution of air, hyper pigmentation of skin, religious clothing patterns, special dietary habits, and inadequate dietary intake of vitamin D [16]. Ahvaz in the south of Iran has a climate similar to these Arab countries and high prevalence of vitamin D deficiency despite its southern latitude can be justified in the same manner.

In the present study, sunshine exposure (between $10 \mathrm{AM}$ and $2 \mathrm{PM})$ did not significantly affect serum 25(OH) D3 concentrations in patients, while the levels of $25(\mathrm{OH})$ D3 in healthy counterparts who had low sunshine exposure $(<30 \mathrm{~min})$ were lower $(P<0.005)$ than those of healthy subjects with a high exposure $(>30 \mathrm{~min} / \mathrm{d})$. This discrepancy between sun exposure and concentrations of $25(\mathrm{OH}) \mathrm{D} 3$ was also reported in other studies [20,24].

No significant differences were observed between the consumption of main dietary sources of vitamin D such as fish, egg, butter, and cream in MS patients and healthy controls. Some Previous studies which have compared dietary intake of vitamin $\mathrm{D}$ between MS patients and controls, have also reported similar findings. In a case control study, no significant differences in terms of dairy foods, fish, and eggs intake were observed between cases and controls [25]. In another investigation by Berr et al., intake of milk, 
dairy products, and fish was unrelated to the prevalence of MS [24]. Zhang et al. have also reported that intake of dairy products and fish was not significantly related to the risk of MS [26]. Because a large proportion of the body's vitamin $\mathrm{D}$ requirement is synthesized via sun exposure, these findings are rational. Our results also showed that there is no significant association between fish consumptions and serum $25(\mathrm{OH}) \mathrm{D} 3$ concentrations in both groups. In contrast, In a study on healthy peri- and postmenopausal Japanese women, it has been reported that $25(\mathrm{OH}) \mathrm{D}$ concentration of subjects who consumed fish frequently ( $\leq 4$ times/wk) was $10.1 \mathrm{nmol} / \mathrm{L}$ higher than that of subjects with a moderate consumption of fish (1-3 times/wk) [27]. It is worth mentioning that fish consumption in Japan is much higher than that of Iran (70 kg/y versus $2.6 \mathrm{~kg} / \mathrm{y}$ per capita, resp.), and Japan has one of the highest rates of fish consumption in the world.

Just few previous studies have compared the serum levels of TAS between MS patients and healthy subjects. According to the results of a study by Visconti et al. [28], there was no significant difference between the means of serial measures of serum antioxidant capacity in patients with first demyelinating episode (FDE) compared with a healthy population over a six-month period. On the other hand, Besler and Çomoğlu [29] have reported that MS patients had significantly lower plasma total antioxidant capacity compared with the control group. It seems necessary to note that, in the latter study, secondary progressive MS patients who first experienced exacerbations were recruited. In the present study, however, patients diagnosed as relapsing-remitting MS were included in the study during an attack-free phase. Variations in MS phases and disease severity may cause these discrepancies. Our results are in agreement with those of Koch et al.s study [30] that found that serum total antiradical activity (ARA) and total antioxidant activity (AOA) were not significantly different between MS patients and healthy controls. However, our findings do not support those of Acar et al.s [12] study that reported that MS patients had lower concentrations of total oxidative status (TOS) and TAS compared with healthy controls. These conflicting results are also likely to be related to different clinical conditions and/or different dietary habits of the patients, interactions of pharmacotherapies, or methodological issues [31, 32].

In a study by Besler et al., antioxidant vitamins' levels (alpha tocopherol, beta-carotene, retinol, and ascorbic acid) were decreased in serum of MS patients during an attack, and this was defined to be dependent on the increased oxidative burden as reflected by lipid peroxidation products [32]. In another study, MS patients had significantly lower serum uric acid levels in comparison with healthy donors. Also the authors found that MS patients with relapse had significantly lower serum uric acid levels compared with MS patients in remission phase [31]. It is noteworthy that the total antioxidant defense status of a cell determines the susceptibility of cells to oxidative stress instead of measuring the concentration of individual antioxidants (e.g., uric acid, antioxidant vitamins, bilirubin, and glutathione) or antioxidant enzymes (e.g., glutathione peroxidase and superoxide dismutase) [30]. Our results showed that there was no significant difference in consumption of dietary antioxidant sources between the 2 groups. However, the intake of all antioxidant vitamins in both groups was well below the dietary reference intake (DRI). The results of some other studies were also in accordance with our findings $[10,24,25]$. For example, in a large cohort study, Zhang et al. [10] found no associations between intake of fruits and vegetables and risk of MS.

One potential source of bias in the present and other retrospective studies could be due to this fact that patients may change their dietary habits because of clinical symptoms of MS before they were diagnosed with MS. Also the small sample size of the present study can be considered as a limitation.

In conclusion, we could not detect any differences between vitamin D and TAS between MS and healthy matched subjects. Dietary intake of vitamin D and antioxidant vitamins also showed no significant differences between the 2 groups. According to the Cochrane review of Farinotti et al. [33], evidence on the possible benefits and risks of vitamin supplementation and antioxidant supplements in MS is lacking. At the moment, more researches are required to assess the effectiveness of dietary interventions in MS.

\section{Conflict of Interests}

The authors declare that there is no conflict of interests regarding the publication of this paper.

\section{References}

[1] V. Shaygannejad, M. Janghorbani, F. Ashtari, and H. Dehghan, "Effects of adjunct low-dose vitamin d on relapsing-remitting multiple sclerosis progression: preliminary findings of a randomized placebo-controlled trial," Multiple Sclerosis International, vol. 2012, Article ID 452541, 7 pages, 2012.

[2] S. Katsavos and M. Anagnostouli, "Biomarkers in multiple sclerosis: an up-to-date overview," Multiple Sclerosis International, vol. 2013, Article ID 340508, 20 pages, 2013.

[3] R. Furlan, M. Rovaris, F. M. Boneschi et al., "Immunological patterns identifying disease course and evolution in multiple sclerosis patients," Journal of Neuroimmunology, vol. 165, no. 1-2, pp. 192-200, 2005.

[4] J. Correale, M. C. Ysrraelit, and M. I. Gaitn, "Immunomodulatory effects of vitamin D in multiple sclerosis," Brain, vol. 132, part 5, pp. 1146-1160, 2009.

[5] I. A. F. van der Mei, A. Ponsonby, T. Dwyer et al., "Past exposure to sun, skin phenotype, and risk of multiple sclerosis: case-control study," The British Medical Journal, vol. 327, no. 7410, pp. 316-320, 2003.

[6] K. L. Munger, S. M. Zhang, E. O’Reilly et al., "Vitamin D intake and incidence of multiple sclerosis," Neurology, vol. 62, no. 1, pp. 60-65, 2004.

[7] J. M. Lemire and D. C. Archer, "1,25-Dihydroxyvitamin D3 prevents the in vivo induction of murine experimental autoimmune encephalomyelitis," Journal of Clinical Investigation, vol. 87, no. 3, pp. 1103-1107, 1991.

[8] M. T. Cantorna, C. E. Hayes, and H. F. Deluca, "1,25-dihydroxyvitamin D3 reversibly blocks the progression of relapsing encephalomyelitis, a model of multiple sclerosis," Proceedings of 
the National Academy of Sciences of the United States of America, vol. 93, no. 15, pp. 7861-7864, 1996.

[9] G. Ferretti, T. Bacchetti, F. Principi et al., "Increased levels of lipid hydroperoxides in plasma of patients with multiple sclerosis: a relationship with paraoxonase activity," Multiple Sclerosis, vol. 11, no. 6, pp. 677-682, 2005.

[10] S. M. Zhang, M. A. Hernán, M. J. Olek, D. Spiegelman, W. C. Willett, and A. Ascherio, "Intakes of carotenoids, vitamin C, and vitamin E and MS risk among two large cohorts of women," Neurology, vol. 57, no. 1, pp. 75-80, 2001.

[11] E. Miller, M. Mrowicka, K. Malinowska, J. Mrowicki, J. SalukJuszczak, and J. Kędziora, "Effects of whole-body cryotherapy on a total antioxidative status and activities of antioxidative enzymes in blood of depressive multiple sclerosis patients," World Journal of Biological Psychiatry, vol. 12, no. 3, pp. 223-227, 2011.

[12] A. Acar, M. U. Cevik, O. Evliyaoglu et al., "Evaluation of serum oxidant/antioxidant balance in multiple sclerosis," Acta Neurologica Belgica, vol. 112, no. 3, pp. 275-280, 2012.

[13] C. H. Polman, S. C. Reingold, G. Edan et al., "Diagnostic criteria for multiple sclerosis: 2005 revisions to the 'McDonald criteria," Annals of Neurology, vol. 58, no. 6, pp. 840-846, 2005.

[14] P. Lips, "Vitamin D deficiency and secondary hyperparathyroidism in the elderly: consequences for bone loss and fractures and therapeutic implications," Endocrine Reviews, vol. 22, no. 4, pp. 477-501, 2001.

[15] N. J. Miller, C. Rice-Evans, M. J. Davies, V. Gopinathan, and A. Milner, "A novel method for measuring antioxidant capacity and its application to monitoring the antioxidant status in premature neonates," Clinical Science, vol. 84, no. 4, pp. 407-412, 1993.

[16] S. Hashemipour, B. Larijani, H. Adibi et al., "Vitamin D deficiency and causative factors in the population of Tehran," BMC Public Health, vol. 4, article 38, 2004.

[17] V. Shaygannejad, K. Golabchi, S. Haghighi, H. Dehghan, and A. Moshayedi, "A comparative study of $25(\mathrm{OH})$ vitamin D serum levels in patients with multiple sclerosis and control group in Isfahan, Iran," International Journal of Preventive Medicine, vol. 1, no. 3, pp. 195-201, 2010.

[18] S. Ozgocmen, S. Bulut, N. Ilhan, A. Gulkesen, O. Ardicoglu, and Y. Özkan, "Vitamin D deficiency and reduced bone mineral density in multiple sclerosis: effect of ambulatory status and functional capacity," Journal of Bone and Mineral Metabolism, vol. 23, no. 4, pp. 309-313, 2005.

[19] B. D. Mahon, S. A. Gordon, J. Cruz, F. Cosman, and M. T. Cantorna, "Cytokine profile in patients with multiple sclerosis following vitamin D supplementation," Journal of Neuroimmunology, vol. 134, no. 1-2, pp. 128-132, 2003.

[20] M. Soilu-Hänninen, L. Airas, I. Mononen, A. Heikkilä, M. Viljanen, and A. Hänninen, "25-Hydroxyvitamin D levels in serum at the onset of multiple sclerosis," Multiple Sclerosis, vol. 11, no. 3, pp. 266-271, 2005.

[21] I. A. F. van der Mei, A. Ponsonby, T. Dwyer et al., "Vitamin D levels in people with multiple sclerosis and community controls in Tasmania, Australia," Journal of Neurology, vol. 254, no. 5, pp. 581-590, 2007.

[22] S. Simpson Jr., B. Taylor, L. Blizzard et al., "Higher 25-hydroxyvitamin D is associated with lower relapse risk in multiple sclerosis," Annals of Neurology, vol. 68, no. 2, pp. 193-203, 2010.

[23] M. H. Gannage-Yared, R. Chemali, N. Yaacoub, and G. Halaby, "Hypovitaminosis D in a sunny country: relation to lifestyle and bone markers," Journal of Bone and Mineral Research, vol. 15, no. 9, pp. 1856-1862, 2000.

[24] C. Berr, J. Puel, M. Clanet, J. B. Ruidavets, J. L. Mas, and A. Alperovitch, "Risk factors in multiple sclerosis: a populationbased case-control study in Hautes-Pyrenees, France," Acta Neurologica Scandinavica, vol. 80, no. 1, pp. 46-50, 1989.

[25] A. Antonovsky, U. Leibowitz, H. A. Smith et al., "Epidemiologic study of multiple sclerosis in Israel. I. An overall review of methods and findings," Archives of Neurology, vol. 13, pp. 183193, 1965.

[26] S. M. Zhang, W. C. Willett, M. A. Hernán, M. J. Olek, and A. Ascherio, "Dietary fat in relation to risk of multiple sclerosis among two large cohorts of women," The American Journal of Epidemiology, vol. 152, no. 11, pp. 1056-1064, 2000.

[27] K. Nakamura, M. Nashimoto, Y. Hori, and M. Yamamoto, "Serum 25-hydroxyvitamin D concentrations and related dietary factors in peri- and postmenopausal Japanese women," The American Journal of Clinical Nutrition, vol. 71, no. 5, pp. 1161-1165, 2000.

[28] A. Visconti, R. Cotichini, S. Cannoni et al., "Concentration of elements in serum of patients affected by multiple sclerosis with first demyelinating episode: a six-month longitudinal follow-up study," Annali dell'Istituto Superiore di Sanita, vol. 41, no. 2, pp. 217-222, 2005.

[29] H. T. Besler and S. Çomoğlu, "Lipoprotein oxidation, plasma total antioxidant capacity and homocysteine level in patients with multiple sclerosis," Nutritional Neuroscience, vol. 6, no. 3, pp. 189-196, 2003.

[30] M. W. Koch, G. S. M. Ramsaransing, A. V. Arutjunyan et al., "Oxidative stress in serum and peripheral blood leukocytes in patients with different disease courses of multiple sclerosis," Journal of Neurology, vol. 253, no. 4, pp. 483-487, 2006.

[31] G. Toncev, B. Milicic, S. Toncev, and G. Samardzic, "Serum uric acid levels in multiple sclerosis patients correlate with activity of disease and blood-brain barrier dysfunction," European Journal of Neurology, vol. 9, no. 3, pp. 221-226, 2002.

[32] H. T. Besler, S. Omoǧlu, and Z. Oku, "Serum levels of antioxidant vitamins and lipid peroxidation in multiple sclerosis," Nutritional Neuroscience, vol. 5, no. 3, pp. 215-220, 2002.

[33] M. Farinotti, L. Vacchi, S. Simi, C. Di Pietrantonj, L. Brait, and G. Filippini, "Dietary interventions for multiple sclerosis," Cochrane Database of Systematic Reviews, vol. 12, Article ID CD004192, 2012. 


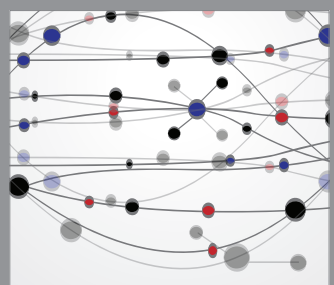

The Scientific World Journal
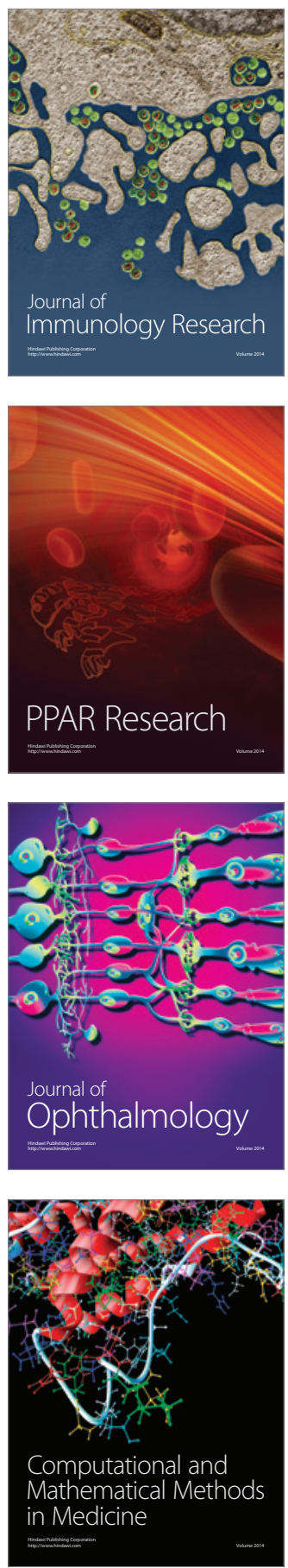

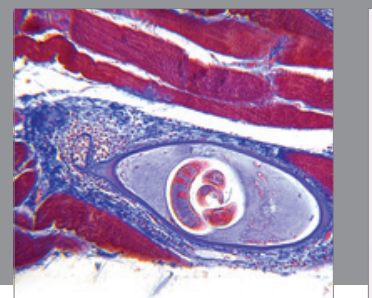

Gastroenterology

Research and Practice
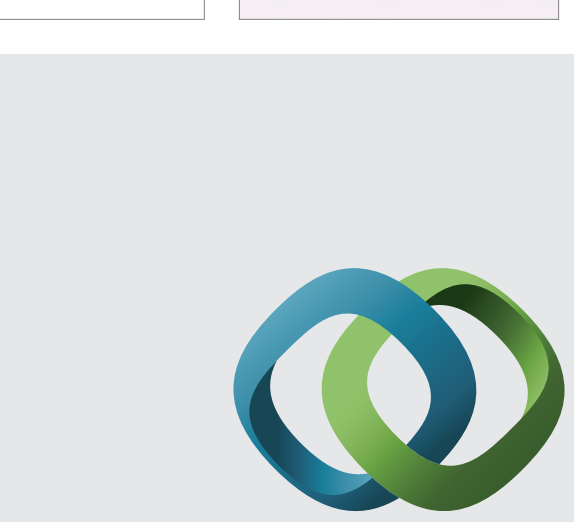

\section{Hindawi}

Submit your manuscripts at

http://www.hindawi.com
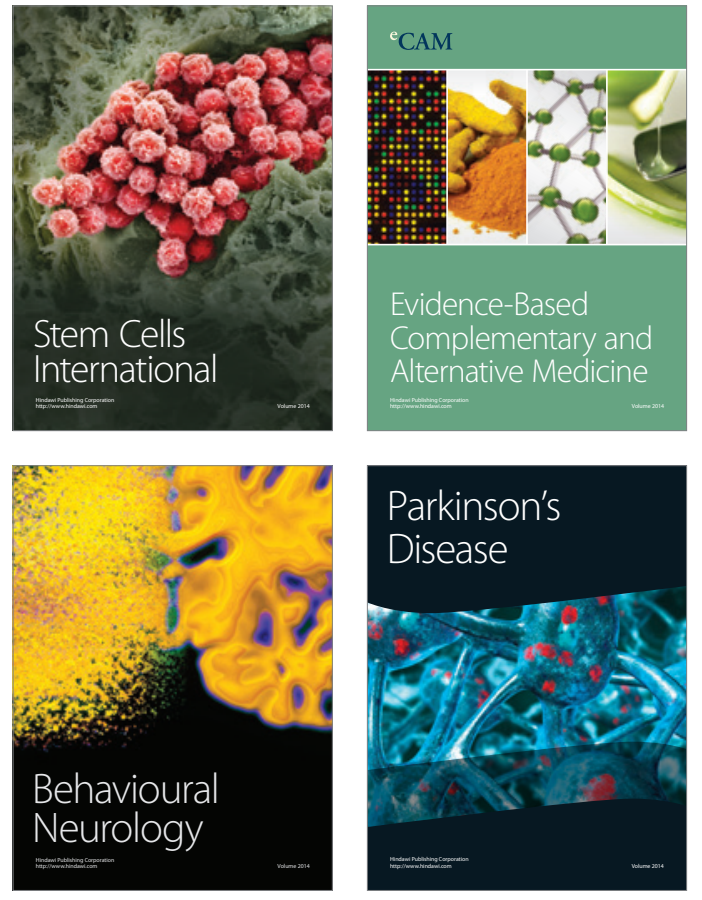
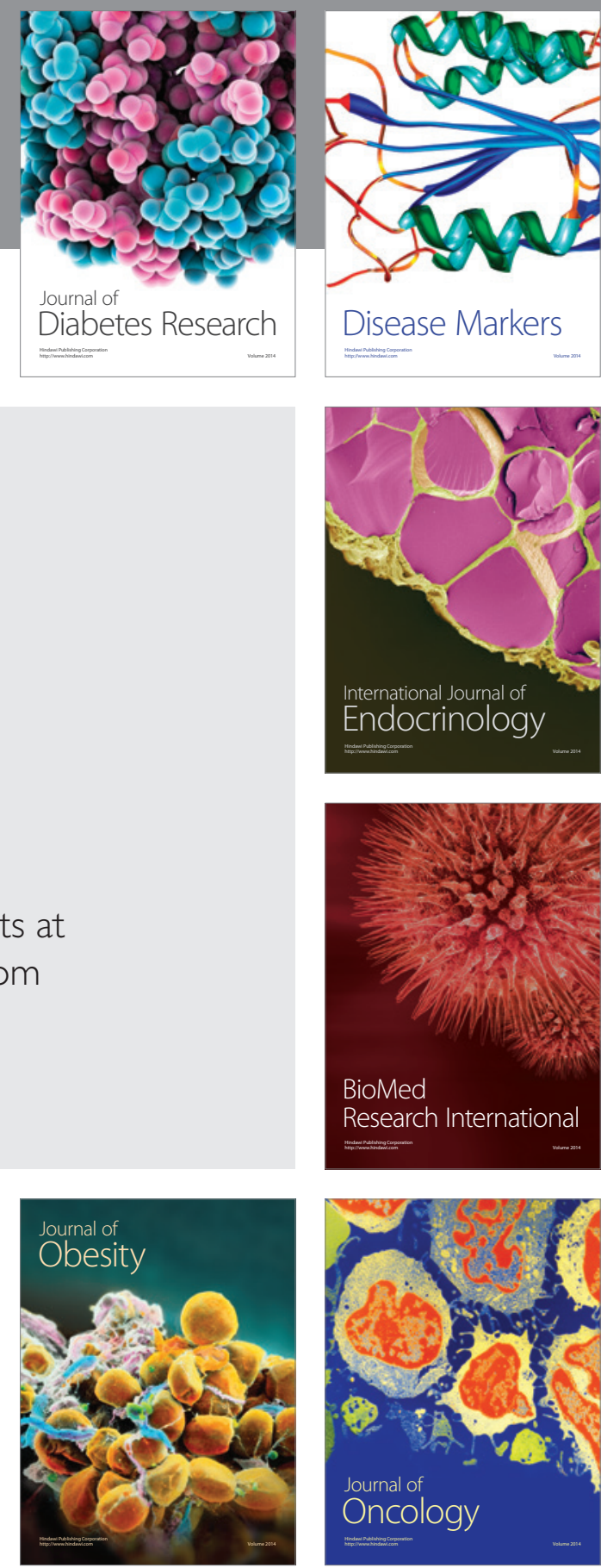

Disease Markers
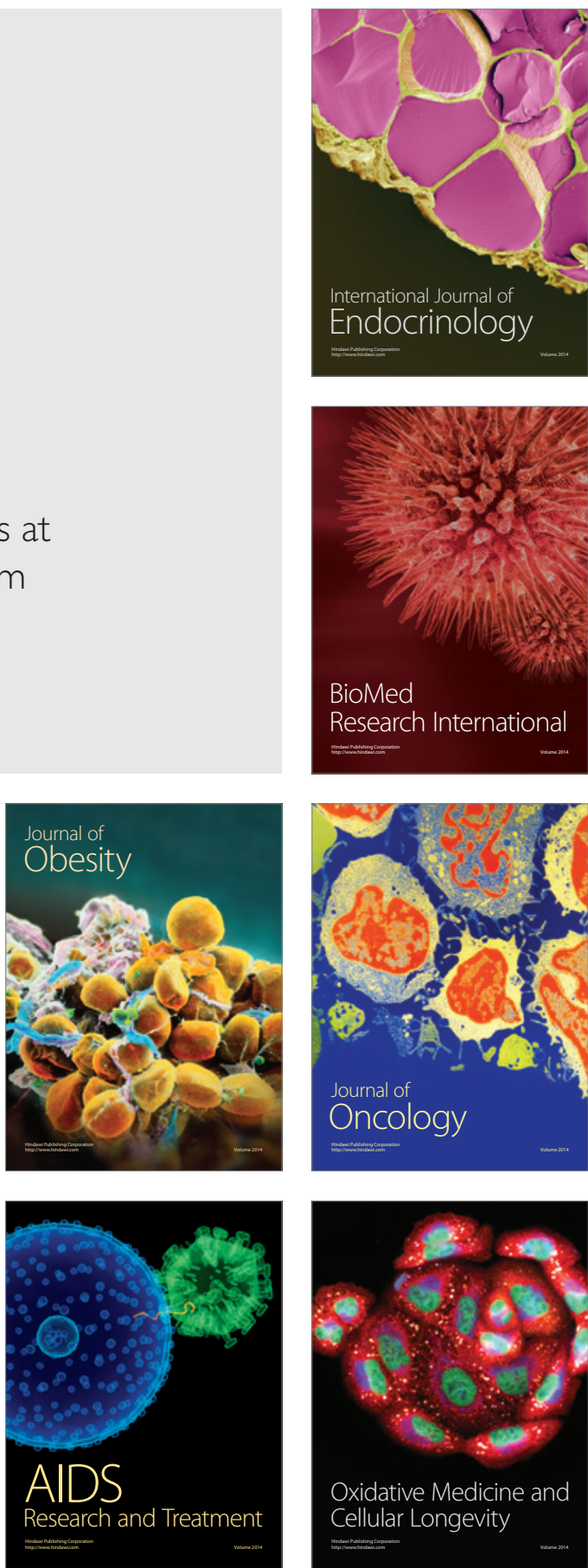